\title{
Mueller Weiss syndrome - case report
}

\section{Síndrome de Mueller-Weiss - Relato de caso}

Sergio Elias Nassar De Marchi ${ }^{1 *}$, Soraya Silveira Monteiro ${ }^{2}$, Eloy De Avila Fernandes ${ }^{3}$

${ }_{1}^{1}$ 3rd-year Specializing Physician in Radiology and Imaging Diagnosis at Hospital do Servidor Público Estadual (lamspe), São Paulo, SP, Brazil.

${ }^{2}$ Radiology Physician at lamspe's Radiology Unit, Hospital do Servidor Público Estadual, and at the Department of Imaging Diagnosis of the Federal University of São Paulo (Unifesp), São Paulo, SP, Brazil. ${ }^{3}$ Radiology Physician employed by the Hospital do Servidor Público Estadual (lamspe), and physician employed by the Department of Imaging Diagnosis of the Federal University of São Paulo (Unifesp), São Paulo, SP Brazil.

Study carried out by the Hospital do Servidor Público Estadual - Francisco Morato de Oliveira HSPE/FMO, São Paulo, SP, Brazil.

\section{CASE RePort}

Male patient, 51 years old, followed up at the rheumatology outpatient clinic of the Hospital do Servidor Público Estadual (Institute of Medical Assistance to Public Servants of the State - Iamspe-SP), complaining of pain in his feet for 13 years and previous diagnosis of valgus flat foot, fibromyalgia, bilateral calcaneocuboid-talonavicular joint osteoarthrosis, and acromioclavicular osteoarthrosis bilaterally, with no osteonecrosis-related diseases. Now reports burning pain in his left foot that worsens with ambulation in recent weeks. The patient underwent magnetic resonance imaging (MRI) of both feet for diagnostic investigation.

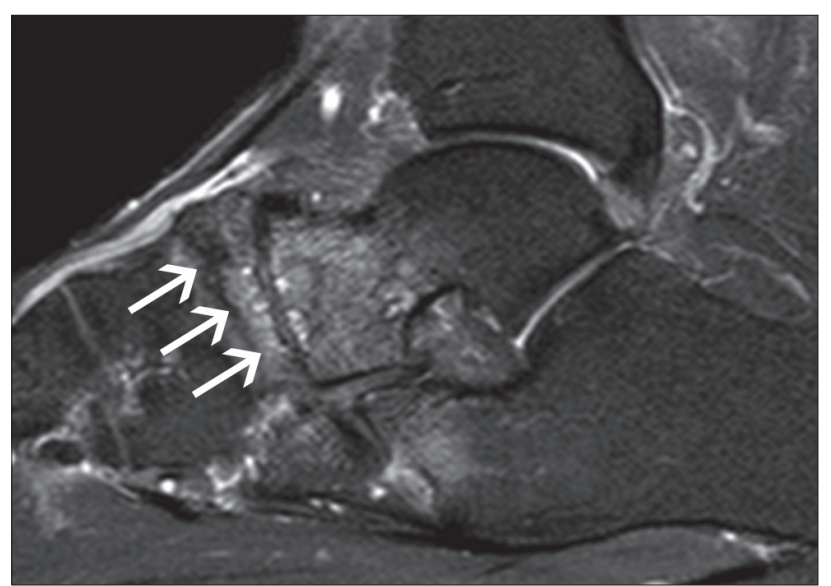

FIGURE 1 T2-weighted sagittal MRI of the left foot weighted in T2 fat sat, demonstrating flattening with deformity similar to a "comma" of the navicular bone (arrows), a pattern of bone edema and subchondral cysts in the talus and navicular bones.

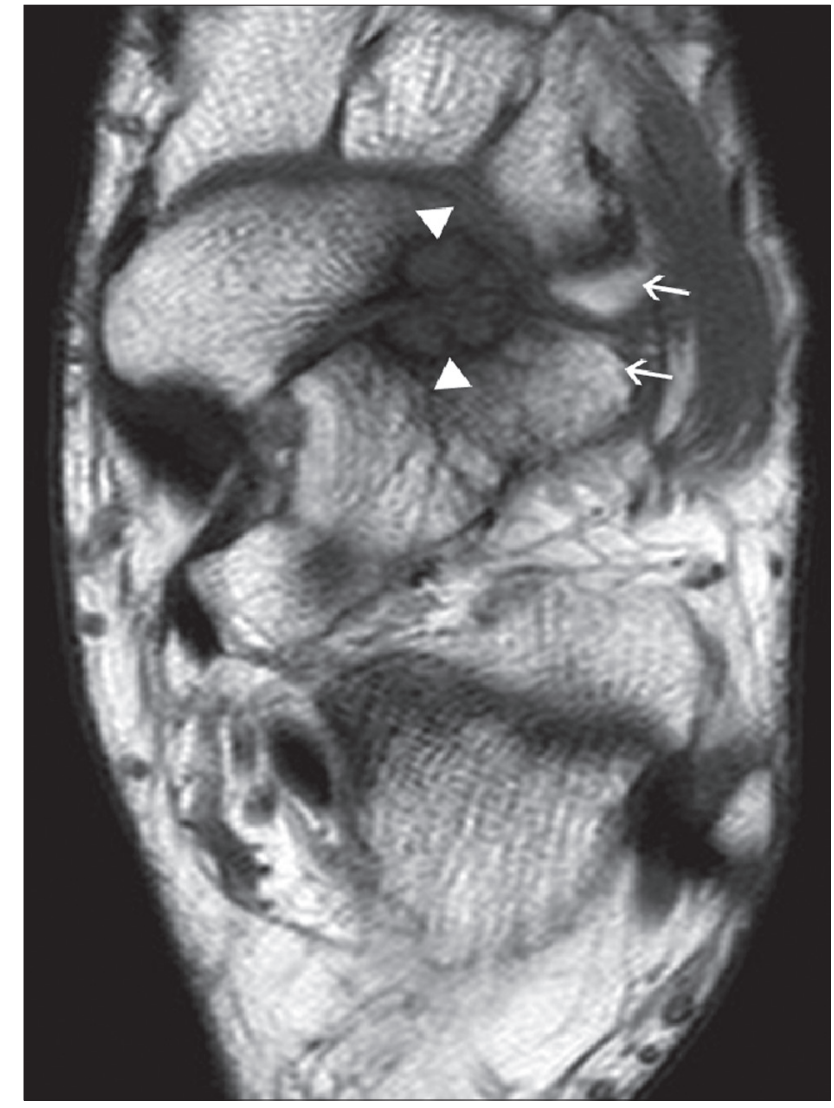

FIGURE 2 T1-weighted transversal MRI of the left foot, showing thinning of the side of the navicular bone, with secondary degenerative talonavicular arthropathy, where sclerosis and subchondral cysts are seen (arrow heads). Approximation of the bony surfaces of the talus and the lateral cuneiform bone (arrow) can be observed. 


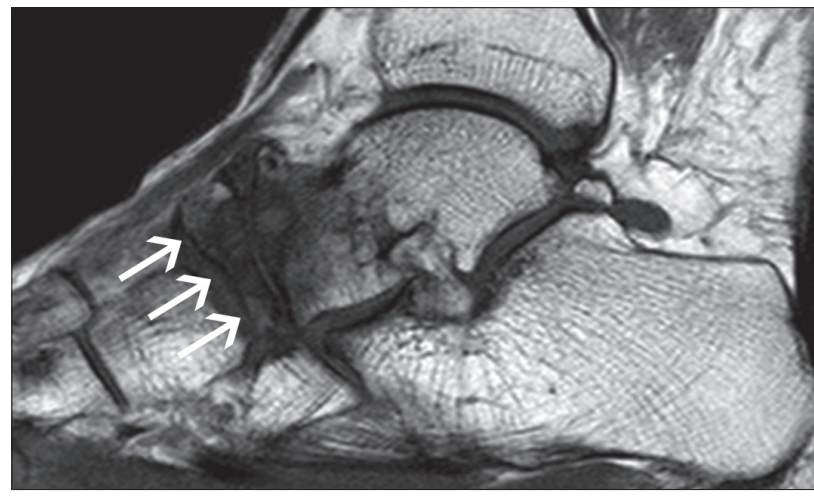

FIGURE 3 T1-weighted sagittal MRI of the right foot, showing thinning with deformity similar to a "comma" of the navicular bone (arrows), a pattern of bone edema and subchondral cysts in the talus and navicular bones.

\section{Discussion}

The Mueller-Weiss syndrome is a rare disease that affects adults, usually between 40 and 60 years of age, is more common in women, and is characterized by compression of the navicular bone between the talus and the lateral cuneiform bone, leading to spontaneous osteonecrosis of the navicular bone. ${ }^{1}$ Symptoms are chronic, with severe pain in the midfoot and progressive deformity. ${ }^{2}$

Not to be confused with Koehler disease (osteonecrosis of the navicular bone in children). ${ }^{3}$ When diagnosed early, disease progression can be prevented through non-surgical treatments, producing an improvement in the patient's quality of life. ${ }^{1}$

The radiographic stages range from minimal changes to the navicular bone, medial or dorsal deviation of part or the entire navicular bone, and a comma-shaped deformity, due to the collapse of the lateral portion until complete fragmentation of the navicular bone, forming a talocuneiform joint in more severe cases. ${ }^{3}$ Bilateral findings, asymmetric involvement and association with pathological fractures are common. ${ }^{2}$

\section{References}

1. Quintella DC, Calmon TR, Guimarães MF, Dos Santos AASMD, Reis M Síndrome de Müeller-Weiss: aspectos radiográficos. Radiol Bras 2009; 42(Supl 1):1-115

2. Rosenberg ZS, Beltran J, Bencardino JT. From the RSNA Refresher Courses. Radiological Society of North America. MR imaging of the ankle and foot Radiographics 2000; 20(Spec No.):S153-79.

3. Haller J, Sartoris DJ, Resnick D, Pathria MN, Berthoty D, Howard B et al. Spontaneous osteonecrosis of the tarsal navicular in adults: imaging findings. AJR Am J Roentgenol 1988; 151(2):355-8 